\title{
Generating regional precipitation from observed and GCM synoptic-scale pressure fields, southern Alberta, Canada
}

\author{
I. R. Saunders*, J. M. Byrne \\ Water Resources Institute, University of Lethbridge, Lethbridge, Alberla, Canada T1K 3M4
}

\begin{abstract}
Observed (1960 to 1989) synoptic-scale fields of sea level pressure (SLP) and $50 \mathrm{kPa}$ geopotentials were objectively typed using the Kirchhofer technique to determine the frequency of occurrence of weather patterns in western Canada. Twenty different synoptic types were generated for both variables (SLP and $50 \mathrm{kPa}$ ) and compared to those simulated in the CCC GCM (Canadian Climate Centre's general circulation model). The SLP fields were poorly simulated by the GCM, but the $50 \mathrm{kPa}$ fields were reliable. Calculation of the precipitation efficiencies for 1960-69 allowed a quantitative assessment of the mean amount of precipitation which each $50 \mathrm{kPa}$ synoptic type brings to southern Alberta in each month. This information was used to generate synthetic precipitation for southern Alberta from (1) observed synoptic climatology for 1970-89, and (2) $1 \times \mathrm{CO}_{2}$ and $2 \times \mathrm{CO}_{2}$ runs of the CCC GCM. For (1), total amounts of synthetic precipitation during 1970-89 approximate the observed values, but the variability is much less. For (2), using the $1 \times \mathrm{CO}_{2}$ run of the CCC GCM to generate synthetic precipitation scenarios gives more realistic amounts than the precipitation modelled by the GCM itself, although the variability is poorly replicated. The GCM suggests little change in the synoptic control of precipitation arising from a doubling of $\mathrm{CO}_{2}$
\end{abstract}

KEY WORDS. Synoptic climatology $\cdot$ Precipitation $\cdot$ Downscalıng $\cdot$ Clımate change

\section{INTRODUCTION}

Current studies of the potential impacts of regional climate change focus strongly on the use of output from general circulation models (GCMs) which are, by definition, not designed for this scale of analysis. A typical approach in these instances is to use GCM data from grid squares in and around the study area and apply development techniques to generate a $2 \times \mathrm{CO}_{2}$ climate scenario. We have previously used the Canadian Climate Centre's (CCC) second-generation spectral GCM (hereafter termed CCC GCMII) as a foundation for developing $2 \times \mathrm{CO}_{2}$ climate scenarios. However, temperature and precipitation are not simulated with sufficient reliability to use with confidence (Saunders \& Byrne 1994); although the spatially averaged mean temperature is reasonably well reproduced

\footnotetext{
•E-mail: saundersi@hg.uleth.ca
}

for the Canadian prairies, the precipitation simulation is less successful. In its favor, the best-simulated season in the CCC GCMII is the summer, which is encouraging since it is the time when most precipitation falls. However, since a significant part of the water supply to the area is derived from runoff generated by mountain snowpacks, and therefore ultimately from winter snowfall, high quality climate simulations are needed on a year-round basis.

Given the above observations, it is beneficial to explore alternative and independent approaches to deriving precipitation for a $2 \times \mathrm{CO}_{2}$ atmosphere. The present study attempted to derive grid-scale precipitation data from synoptic-scale fields of atmospheric pressure by a simple method involving (1) objective classification of synoptic pressure patterns, (2) a simple means of relating the synoptic types to local precipitation amounts, and (3) generating synthetic precipitation time series from GCM-generated pressure fields. The rationale for this approach is founded on the fact 
that synoptic climatology determines many aspects of small-scale surface climate and hydrology, coupled with the general recognition that GCMs give better simulations of large-scale climate than small-scale climate. This has been demonstrated by such studies as Crane \& Barry's (1988) intercomparisons of Arctic sea level pressure (SLP) fields and Hewitson \& Crane's (1992) analyses of SLP patterns over the contiguous United States. In the Pacific Northwest, McKendry et al. (in press) found that the range of pressure fields simulated in the CCC GCMII were generally consistent with observations, although there were differences in the seasonal frequencies.

There are numerous studies which demonstrate that the behaviour of an environmental variable at the surface is related to the synoptic climatology. In the most recent 2 or 3 decades, the technology of climate data acquisition and manipulation has greatly improved, and one advantageous derivative has been the development and application of objective methods of classifying synoptic pressure patterns. Barry (1980) and Yarnal (1993) discuss some of the work in this field. Recent use of synoptic climatology in North America has included comparisons of synoptic type frequencies in relation to spatial and temporal changes in climatic and other environmental variables at the surface. For example, Barry et al. (1981) assessed recent climatic fluctuations in the western United States using SLP patterns classified by the Kirchhofer method. They found that the utility of synoptic typing is limited by the within-type variability of climate, but that at least some of the observed variance in surface temperature and precipitation could be explained by the synoptic climatology. More recently, Changnon et al. (1993) demonstrated the influence of $50 \mathrm{kPa}$ synoptic patterns on winter snow accumulation in the (American) Rocky Mountains, relating the April 1st snowpack to the frequency of occurrence of 7 upper-air patterns (originally defined by the California Institute of Technology in 1943). Changes in the frequency of snowpack distribution types were related to changes in synoptic type frequency. SLP and $85 \mathrm{kPa}$ circulation patterns in the northeastern Pacific ocean were related to point precipitation at a station in the Cascade Mountains by Wilson et al. (1991). Alternatively, variables dependent on synoptic forcing have been used as a basis for explaining local climate, such as the use of wind direction and cloud cover by Hay et al. (1991) to define precipitation regimes in the eastern USA.

In western Canada, the important role of synoptic climatology has been recognized and demonstrated for such phenomena as the winter climate on the Pacific coast (Yarnal 1985), the occurrence of wet and dry periods in the prairies (Knox \& Lawford 1990), and the climatic control of forest-fire frequencies (Johnson \&
Wowchuk 1993). The mass balances of alpine glaciers in the western Cordillera respond to synoptic controls (Yarnal 1984a). At Peyto Glacier, in the Alberta Rocky Mountains, synoptic climatology influences the surface boundary-layer characteristics at spatial scales of only a few kilometres (Stenning et al. 1981).

\section{OBJECTIVES}

The present study had the following objectives:

(1) Define the observed synoptic types in the study area;

(2) Compare the observed synoptic type frequencies with those in a GCM control run (i.e. $1 \times \mathrm{CO}_{2}$ atmosphere):

(3) Determine the relation between the occurrence of synoptic weather patterns and precipitation in the southern Alberta grid square:

(4) Determine the changes in the occurrence of synoptic weather patterns arising from a doubling of atmospheric $\mathrm{CO}_{2}$; and

(5) Determine the possible changes in southern Alberta precipitation arising from $\mathrm{CO}_{2}$ doubling by exploiting the relations defined in (3).

The study area covers most of the 3 Canadian prairie provinces, plus the surrounding area (Fig. 1). The area experiences a continental climate. About $75 \%$ of the precipitation falls as rain in the May-September period (Fig. 2), largely through convective activity. Additionally, much of the surface water available for agricultural, industrial and municipal uses is derived from melting of seasonal snow in the Rocky Mountains and

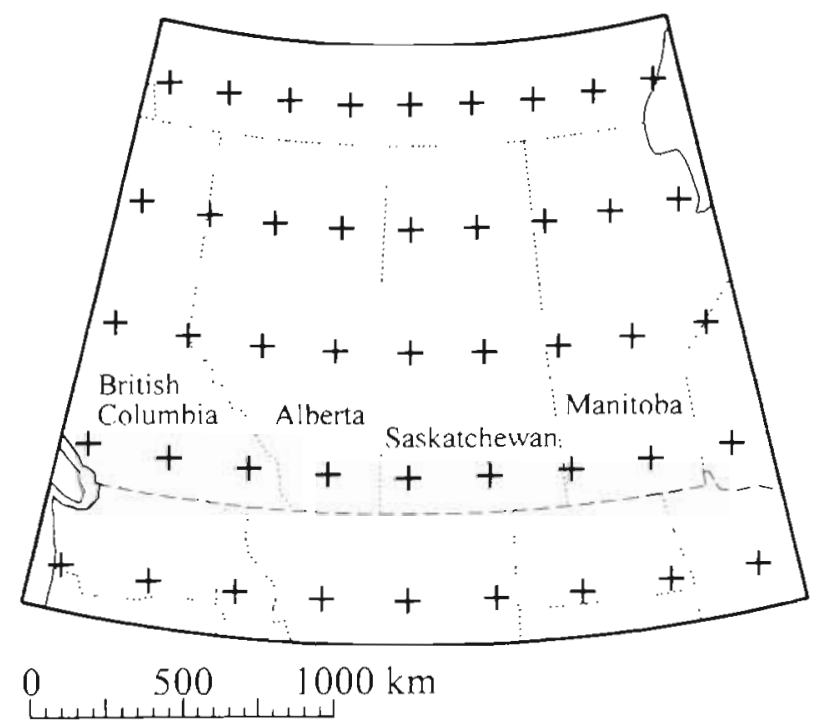

Fig. 1. The study area, western Canada, showing the locations of the 45 grid points used in the analyses 


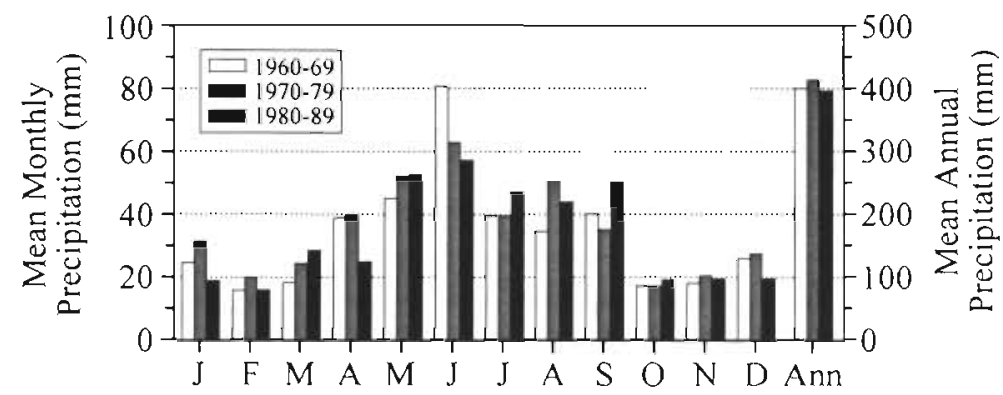

Fig. 2. Decadal means of monthly and annual precipitation for 1960-69 1970-79, and 1980-89 for the southern Alberta grid point (Fig. 1). Total precipitation for the 3 decades is 3977,4217 , and $3950 \mathrm{~mm}$, respectively concluded that the method was a promising means of establishing relations between synoptic climatology and regional environmental variables. Although the specification of thresholds is subjective, a number of studies using the Kirchhofer technique have used identical threshold values, thereby including an element of methodological parity with other published results.

The Kirchhofer method generates a set of characteristic synoptic types from a sample data set by comparing each daily pressure field with all other daily pressure fields, and judging their similarity according to the results of a sums-of-squares difference on the plains. Therefore, precipitation scenarios for this region must be reliable throughout the whole year.

Three databases were used:

(1) $1 \times \mathrm{CO}_{2}$ and $2 \times \mathrm{CO}_{2}$ runs of GCM-simulated daily pressure and precipitation data was extracted from the CCC GCMII. Each run was of 10 yr duration, starting in June, Year 1, and ending at May, Year 11. The latitude-longitude grid point spacing is about $3.71^{\circ} \times 3.75^{\circ}$, and the study area comprises 45 gridpoints (Fig. 1). Further details of this GCM are described by Boer et al. (1984) and McFarlane et al. (1992). GCM surface pressure at each grid point was converted to sea-level pressure using the hydrostatic equation and gas laws.

(2) Observed daily SLP and $50 \mathrm{kPa}$ geopotential height fields for 1960 to 1989, supplied by the National Center for Atmospheric Research (NCAR). A gridded database sharing the same grid spacing as the CCC GCMII was interpolated from the original $5^{\circ} \times 5^{\circ} \mathrm{grid}$

(3) Observed daily precipitation for 1960 to 1989 , derived for the study area from several hundred weather stations of the Atmospheric Environment Service (Canada), interpolated and gridded to the same grid spacing as the CCC GCMII.

\section{SYNOPTIC CLASSIFICATION METHODS}

\subsection{The Kirchhofer synoptic typing method}

The correlation-based Kirchhofer algorithm described by Yarnal (1984b) was used to separate the observed SLP and $50 \mathrm{kPa}$ data into different synoptic types. Originally used to type synoptic patterns over Europe, it has found widespread utility as a means of synoptic classification (e.g. Barry et al. 1981, Yarnal 1984a, Crane \& Barry 1988). A review of classification methodologies by El-Kadi \& Smithson (1992) rated this method very favorably, and McKendry et al. (in press) approach. In order to avoid seasonality effects, each daily pressure field is converted to a normalized grid using

$$
Z_{i}=\frac{x_{i}-\bar{x}}{\sigma}
$$

where $Z_{i}$ is the normalized value of gridpoint $i, \bar{x}$ and $\sigma$ are the mean and standard deviation of all points of the grid, and $x_{i}$ is the observed gridpoint value. Each normalized daily grid in the 10 yr sample was then compared to all other normalized grids using a sum of squares algorithm:

$$
S=\sum_{i=1}^{N}\left(Z_{a j}-Z_{b i}\right)^{2}
$$

where $S$ is the 'Kirchhofer score', $Z_{a i}$ is the normalized value of gridpoint $i$ on day $a, Z_{b}$, is the normalized value of gridpoint $i$ on day $b$, and $N$ is the number of data points. This procedure generates a set of 'keydays', each keyday being a representative of each synoptic type.

The Kirchhofer score represents the degree of similarity between the spatial patterns on each pair of maps, with lower values of $S$ indicating higher agreement. Since it is possible to produce a low $S$ score while having different spatial patterns represented in any pair of maps, subscore values $S_{\mathrm{R}}$ and $S_{\mathrm{C}}$ for each row and column of the grid are also calculated using a sum of squares algorithm. $S, S_{\mathrm{R}}$ and $S_{\mathrm{C}}$ are then compared with pre-determined threshold values in order to accept or reject spatial similarity between the 2 grids. Setting the thresholds is the only subjective part of the procedure, and changing the values will result in different numbers of synoptic types being generated. All of the threshold values used in this study were in accordance with other users of the Kirchhofer technique (e.g. Yarnal 1985): pairs of $50 \mathrm{kPa}$ grids are considered to be similar if $S<0.5 N$, and row and column scores $S_{\mathrm{R}}$ and $S_{\mathrm{C}}$ are less than $1.0 N_{\mathrm{R}}$ and $1.0 N_{\mathrm{C}}$ respectively (where $N_{\mathrm{R}}$ and $N_{\mathrm{C}}$ equal the number of grid points in the rows and columns). The greater spatial 
variability in SLP fields requires slightly more tolerant threshold values to prevent an overabundance of synoptic types being generated, and pairs of grids are considered to be spatially similar when $S<1.0 \mathrm{~N}$ and $S_{\mathrm{R}}$ and $S_{C}$ are less than $1.8 N_{R}$ and $1.8 N_{C}$

The day with the most Kirchhofer scores meeting the threshold criteria is designated as 'Keyday 1' and is considered to be representative of synoptic Type 1. This keyday, and all the days with which it is deemed to be similar on the basis of the $S$ scores, are extracted and the analysis repeated with the remaining data to find Keyday 2. The process is reiterated until all of the days in the sample are classified into groups of 5 days or more. The remaining days are considered to be 'unclassified'.

\subsection{Methods}

The above procedure was first applied to the observed pressure fields for western Canada. Since the initial search for keydays is computationally too intensive to be applied to the whole 30 yr data set, the initial generation of synoptic types was derived from a $10 \mathrm{yr}$ sample (1960-1969). Once the initial set of keydays was generated, a second pass through the whole $30 \mathrm{yr}$ database was made, during which Eq. (2) was used to compare each of the designated keydays with all other daily grids. Each day was then assigned a synoptic type number corresponding to the keyday for which the lowest Kirchhofer score (i.e. closest similarity) was produced. Each daily pressure field in the remaining 2 decades (1970-1989) was then assigned Kirchhofer type numbers by using Eq. (2) and correlating the 1960-69 keydays to the $1970-89$ normalized grids.

\section{OBSERVED AND SIMULATED CLIMATOLOGIES}

The 1960-69 NCAR sample was resolved into 20 SLP synoptic types and the same number of $50 \mathrm{kPa}$ synoptic types. For both variables, the frequencies of occurrence of each synoptic type in 1960-69 were virtually indistinguishable from 1970-79 and 1980-89 (Fig. 3); therefore there is no obvious bias in the data arising from climate change within the period 1960-89. Frequencies of occurrence of each synoptic type are shown in Tables $1 \& 2$. For the whole $30 \mathrm{yr}$ period, about $80 \%$ of the days were accounted for by 12 (SLP) or 7 (50 kPa) synoptic types, and only $1.87 \%$ (SLP) or $4.01 \%$ (50 kPa) of the days were unclassified. The synoptic types themselves are illustrated in Figs. 4 $\& 5$. In southern Alberta, the 2 most common SLP types showed northerly or northwesterly flow (SLP Types 1 and 2); Type 1 was especially prevalent in winter, while Type 2 was more common in summer. The third most common type, Type 4 , showed a quasi-zonal westerly flow over the study area. For upper air patterns over southern Alberta, the 2 most predominant types (Types 1 and 2) both showed a strong zonal

Table 1. Percentage occurrence of sea level pressure (SLP) synoptic types in the 1960-89 period, for all data ('Year') and by month. T: synoptic type number; U: unclassified; $M$ : missing. $n=10945$

\begin{tabular}{|c|c|c|c|c|c|c|c|c|c|c|c|c|c|}
\hline$T$ & Year & Jan & Feb & Mar & Apr & May & Jun & Jul & Aug & Sep & Oct & Nov & Dec \\
\hline 1 & 17.47 & 28.92 & 27.02 & 21.61 & 8.56 & 11.61 & 11.56 & 14.19 & 15.59 & 14.56 & 12.37 & 20.00 & 24.09 \\
\hline 2 & 13.34 & 6.56 & 10.71 & 12.04 & 22.89 & 21.29 & 19.78 & 8.28 & 10.75 & 10.67 & 15.05 & 12.44 & 9.78 \\
\hline 3 & 8.31 & 6.56 & 7.86 & 7.96 & 8.44 & 6.67 & 6.89 & 10.00 & 11.51 & 9.56 & 8.82 & 7.00 & 8.39 \\
\hline 4 & 11.89 & 8.92 & 8.57 & 10.75 & 12.78 & 12.47 & 13.89 & 19.03 & 11.72 & 12.78 & 12.90 & 11.56 & 7.10 \\
\hline 5 & 2.96 & 1.94 & 2.26 & 4.19 & 4.00 & 3.87 & 4.00 & 2.58 & 2.04 & 2.78 & 3.12 & 3.22 & 1.51 \\
\hline 6 & 6.79 & 3.12 & 7.26 & 6.56 & 8.33 & 9.03 & 7.78 & 5.70 & 5.16 & 6.89 & 8.82 & 5.56 & 7.31 \\
\hline 7 & 5.47 & 7.85 & 6.90 & 5.38 & 2.67 & 2.04 & 2.89 & 6.99 & 8.39 & 5.22 & 4.19 & 4.56 & 8.49 \\
\hline 8 & 4.68 & 8.49 & 5.00 & 3.44 & 2.67 & 3.55 & 2.67 & 4.41 & 5.05 & 6.56 & 3.55 & 6.00 & 4.73 \\
\hline 9 & 1.35 & 2.04 & 1.43 & 0.54 & 1.22 & 0.75 & 2.11 & 1.83 & 1.72 & 1.89 & 1.08 & 1.00 & 0.65 \\
\hline 10 & 1.58 & 1.72 & 1.55 & 1.18 & 0.78 & 1.61 & 1.33 & 0.75 & 2.69 & 2.44 & 2.58 & 1.67 & 1.83 \\
\hline 11 & 2.55 & 2.26 & 1.55 & 3.98 & 3.67 & 4.09 & 3.78 & 1.51 & 1.94 & 1.56 & 2.69 & 2.11 & 1.40 \\
\hline 12 & 1.46 & 1.08 & 0.71 & 0.54 & 1.22 & 0.75 & 1.44 & 1.94 & 1.94 & 1.67 & 1.18 & 2.11 & 2.90 \\
\hline 13 & 3.62 & 3.87 & 2.50 & 4.62 & 3.11 & 3.76 & 3.78 & 3.76 & 3.33 & 3.89 & 3.23 & 3.78 & 3.66 \\
\hline 14 & 2.37 & 2.80 & 1.90 & 1.08 & 0.89 & 0.75 & 1.67 & 2.90 & 3.44 & 4.33 & 2.69 & 2.78 & 3.23 \\
\hline 15 & 4.04 & 2.80 & 2.02 & 4.73 & 6.33 & 6.02 & 5.33 & 3.98 & 2.90 & 3.00 & 5.16 & 4.00 & 2.04 \\
\hline 1.6 & 2.96 & 2.47 & 2.98 & 4.30 & 4.67 & 4.41 & 3.22 & 1.40 & 2.15 & 2.33 & 2.47 & 3.00 & 2.15 \\
\hline 17 & 1.16 & 0.22 & 0.71 & 0.54 & 1.78 & 1.40 & 1.67 & 1.40 & 1.18 & 1.56 & 1.61 & 1.33 & 0.54 \\
\hline 18 & 2.00 & 2.15 & 2.38 & 2.47 & 2.00 & 2.80 & 2.78 & 1.72 & 1.29 & 1.89 & 1.08 & 1.22 & 2.26 \\
\hline 19 & 2.23 & 1.72 & 2.86 & 1.08 & 1.33 & 1.83 & 1.11 & 1.61 & 2.90 & 2.22 & 3.98 & 3.00 & 3.12 \\
\hline 20 & 1.76 & 2.69 & 1.67 & 0.75 & 1.00 & 0.32 & 1.11 & 3.23 & 2.47 & 2.33 & 1.18 & 1.67 & 2.69 \\
\hline $\mathrm{U}$ & 1.87 & 1.83 & 2.14 & 1.72 & 1.67 & 0.97 & 1.22 & 2.80 & 1.83 & 1.89 & 2.26 & 2.00 & 2.15 \\
\hline M & 0.05 & 0.00 & 0.00 & 0.54 & 0.00 & 0.00 & 0.00 & 0.00 & 0.00 & 0.00 & 0.00 & 0.00 & 0.00 \\
\hline
\end{tabular}



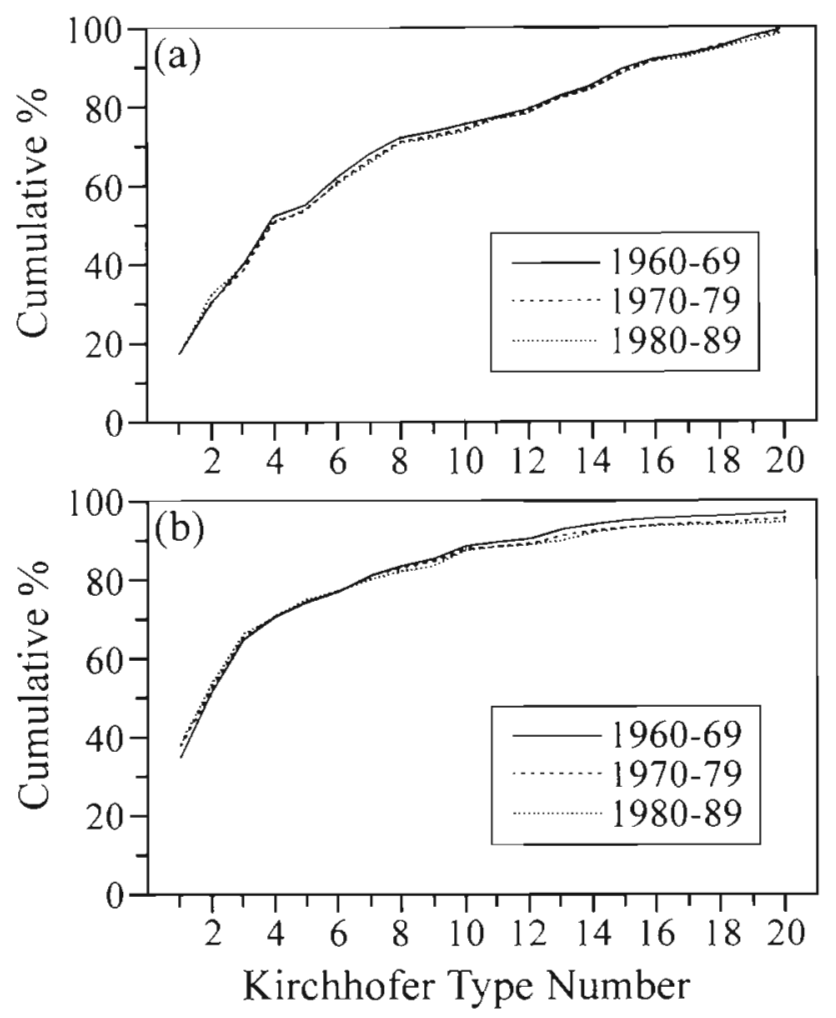

Fig. 3. Cumulative-percent frequency charts of (a) SLP and (b) $50 \mathrm{kPa}$ synoptic types for each of the 3 decades: 1960-69, 1970-79, and 1980-89 component, reflecting the general dominance of the mid-latitude westerlies. Type 3, which was common in winter but rare in summer, was characterized by a strong northwesterly flow, and typified the average position of the polar jet at this time of year.

Applying the Kirchhofer technique to the $10 \mathrm{yr}$ control run of the CCC GCMII SLP and $50 \mathrm{kPa}$ fields produced the frequency distributions seen in Fig. 6. One disturbing feature of the GCM simulation which was immediately apparent is that approximately $16 \%$ of the SLP data were unclassified, and this percentage was larger (about $23 \%$ ) in summer. Additionally, the distribution of synoptic type frequencies differed markedly, with the most commonly observed types (Types 1 and 2) being under-represented in the GCM, and SLP Types 7, 18, 19 and 20 grossly over-represented. For the $50 \mathrm{kPa}$ fields, the GCM results showed much better parity with the observed climatology. This study therefore focused on relating surface precipitation to synoptic fields of $50 \mathrm{kPa}$ geopotential heights.

\section{SYNOPTIC CONTROLS ON PRECIPITATION}

'Precipitation efficiency' is defined as the ratio between the percentage of total precipitation delivered to a location by a particular synoptic type and the frequency of occurrence of that synoptic type (Yarnal 1984 a). It can therefore be employed to determine the

Table 2. Percentage occurrence of $50 \mathrm{kPa}$ synoptic types in the $1960-89$ period, for all data ('Year') and by month. T: synoptic type number; U: unclassified; $M$ : missing. $n=10886$

\begin{tabular}{|c|c|c|c|c|c|c|c|c|c|c|c|c|c|}
\hline $\mathrm{T}$ & Year & Jan & Feb & Mar & Apr & May & Jun & Jul & Aug & Sep & Oct & Nov & Dec \\
\hline 1 & 36.88 & 42.90 & 44.29 & 42.58 & 27.89 & 25.48 & 25.89 & 35.59 & 35.38 & 37.11 & 40.11 & 42.00 & 43.55 \\
\hline 2 & 15.80 & 8.82 & 8.10 & 16.45 & 17.22 & 14.52 & 16.11 & 20.65 & 22.04 & 17.78 & 19.35 & 17.00 & 10.97 \\
\hline 3 & 12.85 & 26.34 & 23.45 & 15.05 & 10.00 & 7.31 & 6.44 & 4.30 & 6.77 & 10.44 & 12.26 & 12.22 & 20.22 \\
\hline 4 & 5.12 & 3.01 & 4.05 & 4.30 & 5.33 & 4.84 & 7.44 & 6.77 & 5.81 & 5.00 & 5.05 & 5.67 & 4.19 \\
\hline 5 & 3.85 & 1.40 & 2.38 & 2.26 & 3.33 & 5.27 & 8.33 & 8.06 & 7.10 & 3.33 & 1.51 & 1.67 & 1.51 \\
\hline 6 & 2.54 & 0.65 & 0.36 & 1.08 & 4.22 & 5.81 & 5.78 & 3.76 & 2.37 & 1.89 & 2.58 & 0.78 & 1.08 \\
\hline 7 & 3.62 & 3.23 & 2.14 & 3.12 & 4.00 & 2.58 & 3.22 & 1.29 & 3.01 & 5.56 & 4.30 & 5.44 & 5.48 \\
\hline 8 & 2.15 & 3.76 & 4.40 & 2.26 & 1.33 & 1.29 & 1.56 & 0.43 & 1.51 & 2.89 & 1.18 & 1.78 & 3.55 \\
\hline 9 & 1.56 & 0.11 & 0.24 & 1.08 & 2.89 & 5.38 & 3.67 & 1.72 & 1.29 & 1.00 & 0.65 & 0.33 & 0.32 \\
\hline 10 & 3.35 & 1.83 & 1.31 & 1.94 & 2.67 & 4.41 & 5.56 & 6.56 & 5.27 & 4.56 & 2.47 & 2.44 & 1.08 \\
\hline 11 & 0.85 & 1.08 & 1.43 & 0.22 & 1.44 & 1.18 & 1.56 & 0.00 & 0.22 & 1.11 & 0.75 & 0.56 & 0.75 \\
\hline 12 & 0.67 & 0.43 & 0.00 & 0.54 & 1.11 & 1.72 & 0.33 & 0.43 & 1.40 & 0.56 & 0.54 & 0.44 & 0.43 \\
\hline 13 & 1.78 & 2.47 & 1.90 & 1.94 & 1.44 & 1.29 & 0.89 & 1.72 & 0.65 & 0.78 & 2.90 & 2.56 & 2.80 \\
\hline 14 & 1.56 & 0.22 & 0.36 & 0.65 & 1.78 & 2.80 & 3.11 & 4.09 & 2.58 & 1.44 & 1.08 & 0.33 & 0.22 \\
\hline 15 & 0.93 & 0.86 & 0.95 & 0.86 & 0.89 & 1.40 & 1.00 & 0.54 & 1.18 & 0.56 & 0.86 & 1.11 & 0.97 \\
\hline 16 & 0.60 & 1.83 & 1.31 & 0.43 & 0.78 & 0.65 & 0.00 & 0.00 & 0.11 & 0.22 & 0.54 & 0.78 & 0.65 \\
\hline 17 & 0.31 & 0.00 & 0.48 & 0.11 & 0.89 & 0.97 & 0.56 & 0.22 & 0.00 & 0.11 & 0.11 & 0.00 & 0.32 \\
\hline 18 & 0.20 & 0.00 & 0.12 & 0.32 & 0.22 & 0.43 & 0.33 & 0.00 & 0.00 & 0.56 & 0.32 & 0.11 & 0.00 \\
\hline 19 & 0.37 & 0.11 & 0.00 & 0.22 & 0.56 & 1.29 & 0.89 & 0.00 & 0.22 & 0.56 & 0.22 & 0.11 & 0.22 \\
\hline 20 & 0.42 & 0.00 & 0.00 & 0.43 & 0.11 & 0.86 & 0.78 & 0.54 & 0.43 & 0.67 & 0.43 & 0.67 & 0.11 \\
\hline $\mathrm{U}$ & 4.01 & 0.97 & 1.90 & 4.19 & 9.44 & 10.54 & 6.56 & 2.58 & 2.37 & 3.44 & 1.61 & 2.89 & 1.61 \\
\hline$M$ & 0.58 & 0.00 & 0.83 & 0.00 & 2.44 & 0.00 & 0.00 & 0.75 & 0.32 & 0.44 & 1.18 & 1.11 & 0.00 \\
\hline
\end{tabular}



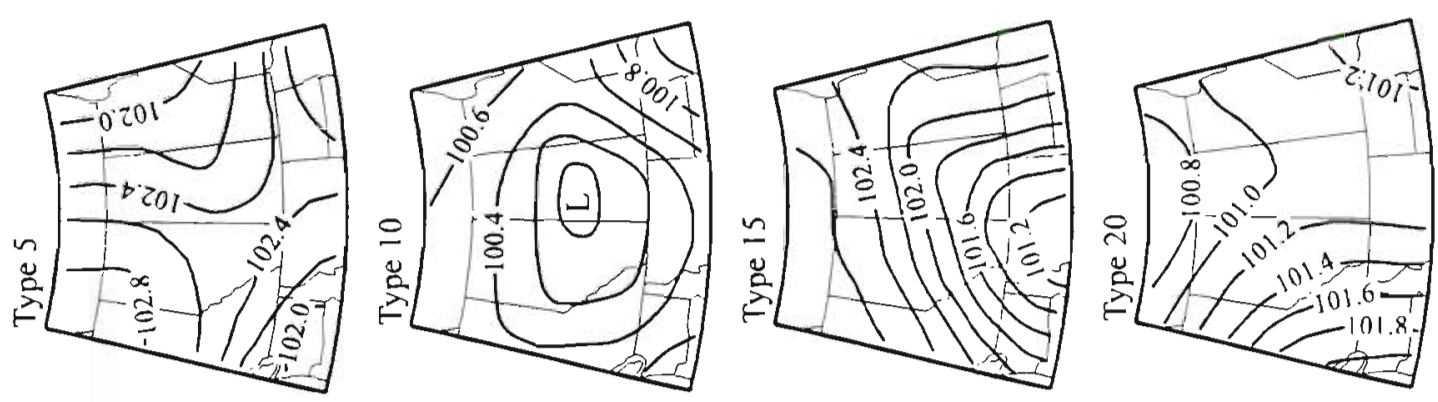

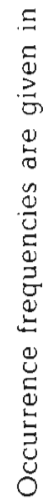
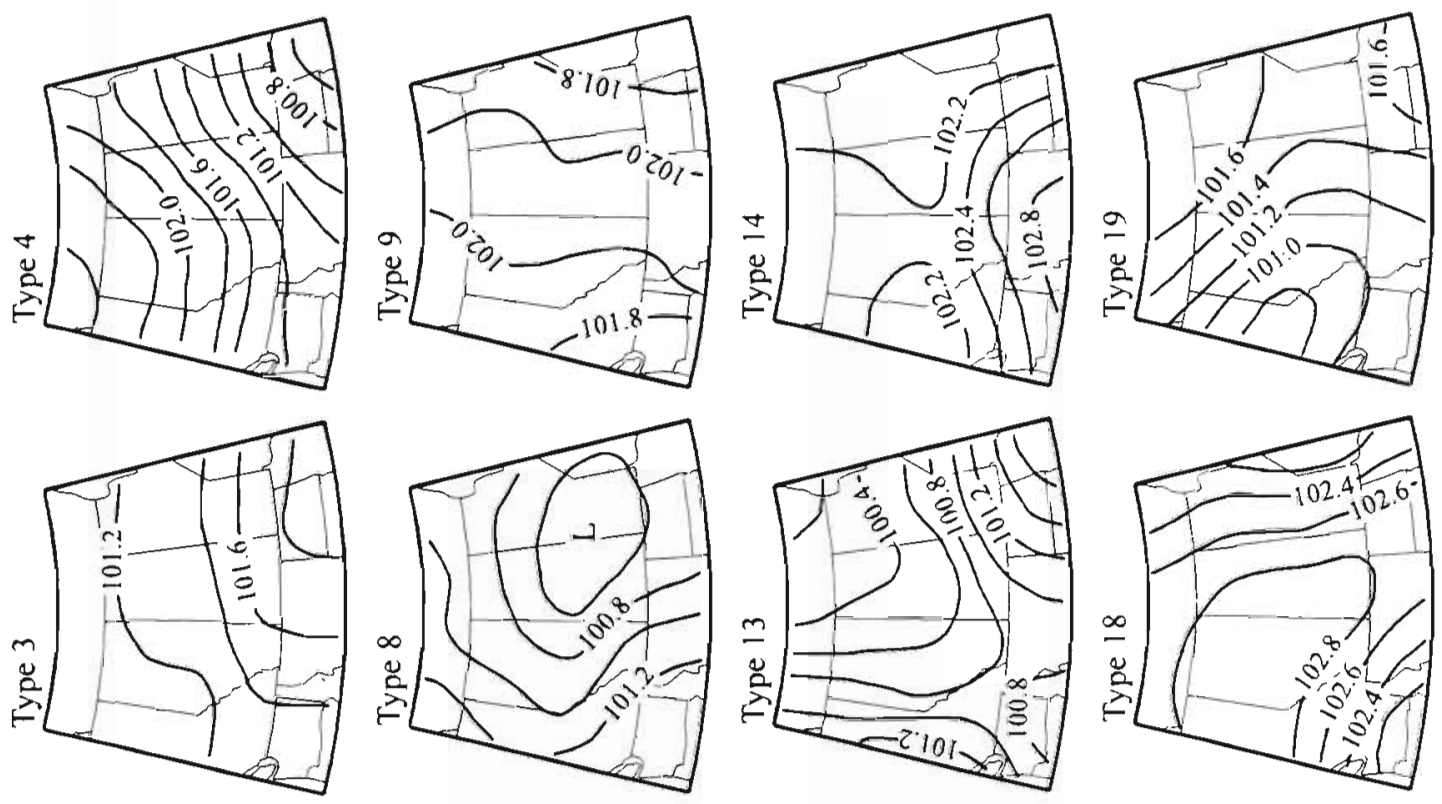

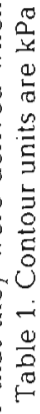
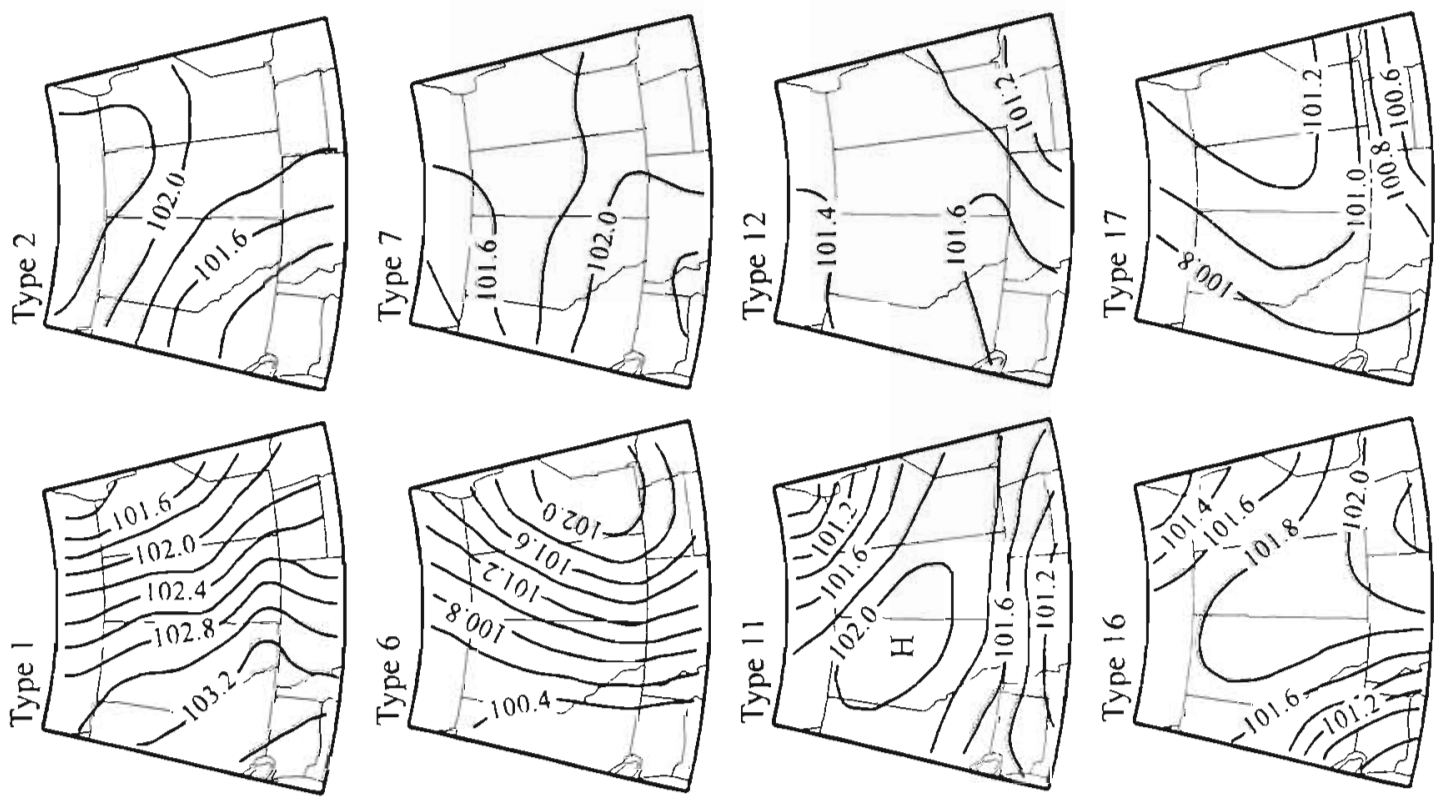

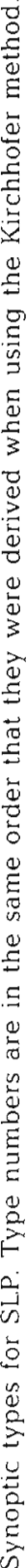

要 

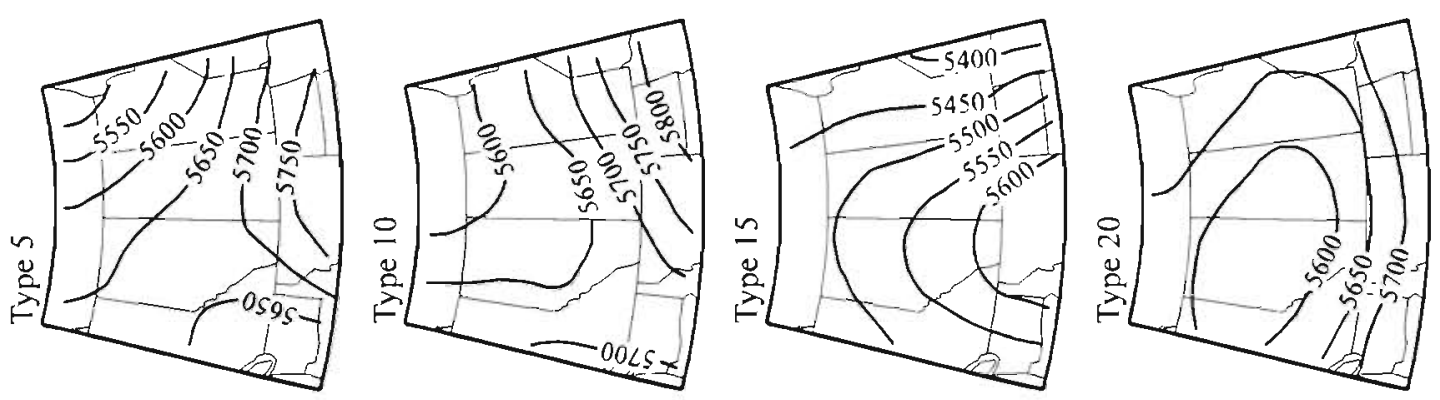

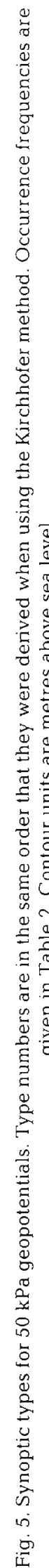
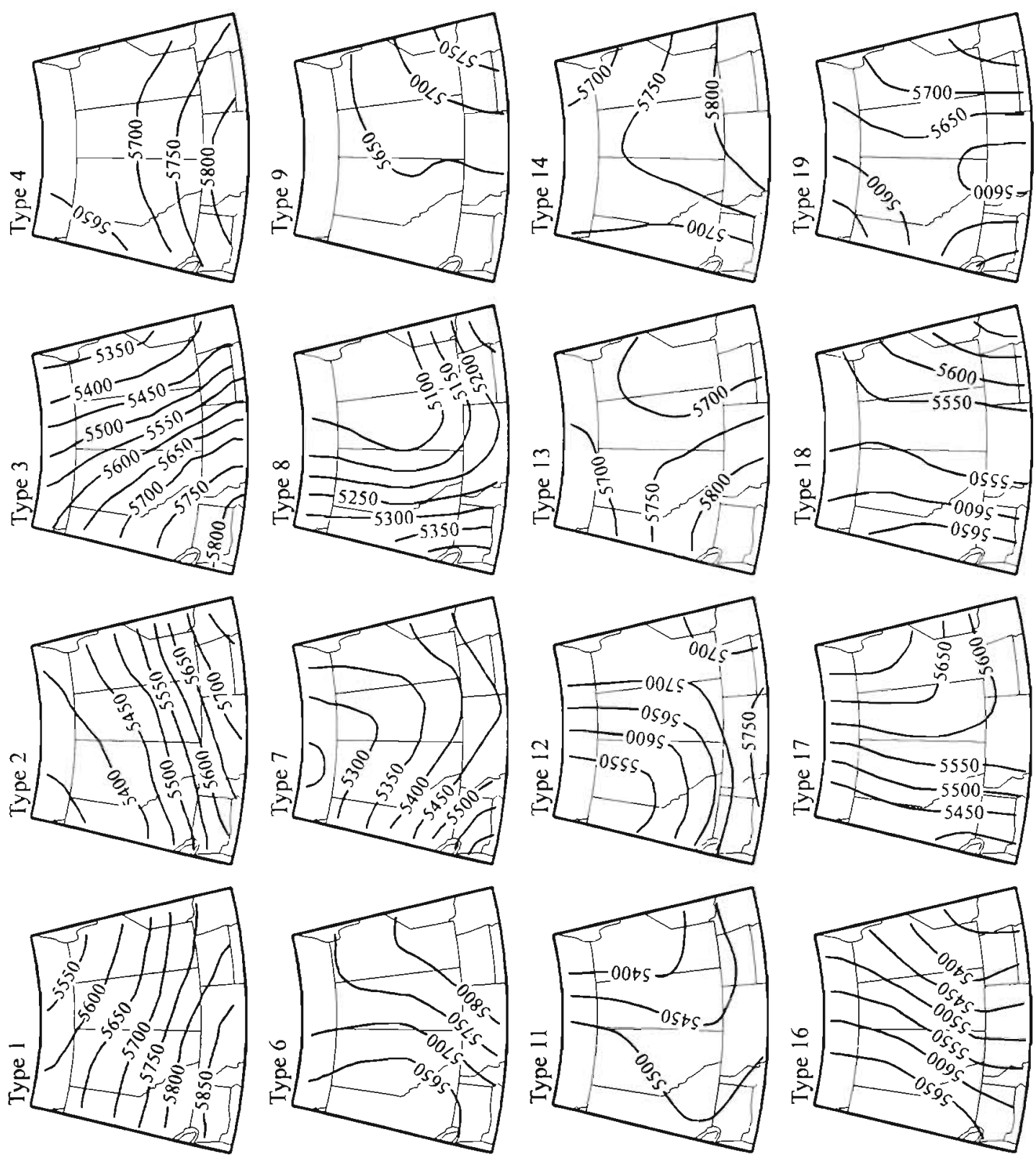

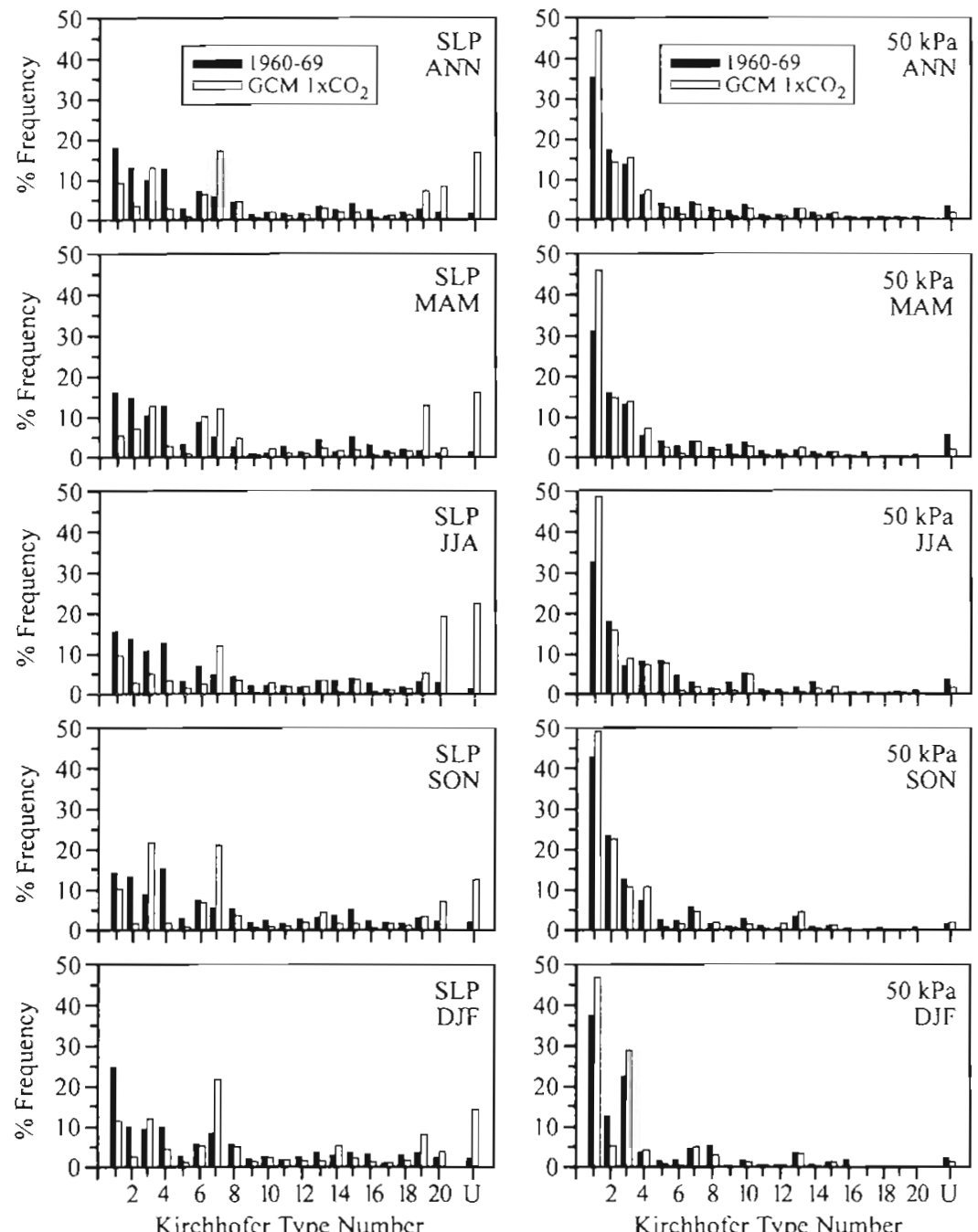

Fig. 6. Histograms of observed (1960-69) and $1 \times \mathrm{CO}_{2}$ GCM-simulated SLP and $50 \mathrm{kPa}$ synoptic type frequencies for annual (ANN) and seasonal (MAM, JJA, SON, DJF) data

relative importance of a given synoptic type to the surface precipitation, and so offers valuable insights into the synoptic controls on small-scale precipitation. So

$$
R_{i j}=\frac{P_{l j}}{f_{i j}} \times 100
$$

where $R_{i j}$ is the precipitation efficiency of synoptic type $i$ in period $j_{1} P_{i j}$ is the percentage of the total precipitation occurring with synoptic type $i$ in period $j$, and $f_{i j}$ is the percentage occurrence of synoptic type $i$ in period $j$. A synoptic type that occurs for $n$ percent of the time and delivers $n$ percent of the total precipitation will therefore have an $R_{i j}$ value of 100 . Values of $R_{i j}$ substantially less than 100 therefore indicate synoptic types that promote dry conditions, and values greatly in excess of 100 indicate types that promote wet conditions. $R_{i,}$ is therefore a measure of the control of synoptic weather on surface water inputs. Conditions at the surface are especially affected by the occurrence or absence of those synoptic types with very high or low precipitation efficiencies. Changes in the frequency of occurrence of these synoptic patterns in a GCM arising from a doubling of atmospheric $\mathrm{CO}_{2}$ could therefore be used to generate new time series of precipitation if a relation with synoptic types could be established. This of course assumes that precipitation efficiencies for any given synoptic type remain the same under $2 \times \mathrm{CO}_{2}$ conditions.

Precipitation efficiencies were calculated for monthly and annual precipitation totals for the southern $\mathrm{Al}$ berta grid square (Fig, 1) using $10 \mathrm{yr}$ (1960-69) of observed $50 \mathrm{kPa}$ pressure data. The results (Table 3 ) indicate that few of the synoptic pressure patterns were consistently efficient at bringing precipitation to the study area. Through most of the summer, when monthly precipitation is greatest, the most commonly occurring zonal $50 \mathrm{kPa}$ pressure fields (Types 1 and 2) persistently had $R_{i j}$ values much less than 100, and only Types 5 and 9 gave $R_{i j}$ values much greater than 100 throughout the whole season. In southern Alberta, these types reflect weakly anticyclonic upper-air flow (Fig. 4), and likely enable localscale convection to develop which would otherwise be suppressed by a stronger regional airflow.

In order to exploit the precipitation efficiency concept for more predictive purposes, $\mathrm{Eq}$. (3) was rearranged to isolate $P_{i j}$ and output the mean amount of daily precipitation which falls per synoptic type in each month. This was applied to the 1960-69 data, and results are shown in Table 4 . The information in this table shows the mean daily precipitation that is expected to fall in southern Alberta for a given $50 \mathrm{kPa}$ pressure pattern and given month. For example, a Type 4 weather pattern occurring on a June day would produce $0.413 \mathrm{~mm}$ of precipitation. Knowledge of the daily synoptic types that occur in a given time frame therefore facilitates the calculation of the tatal precipitation accumulated during that time frame. Although this method is too crude to be able to generate a daily time series, it might be sufficient for generating monthly precipitation totals. As a test of the potential for using this information in a 
Table 3. Precipitation efficiencies for southern Alberta derived from $50 \mathrm{kPa}$ synoptic types, period 1960-69. T: synoptic type number; U: unclassified

\begin{tabular}{|rrrrrrrrrrrrr|r}
\hline T & Year & Jan & Feb & Mar & Apr & May & Jun & Jul & Aug & Sep & Oct & Nov & Dec \\
\hline 1 & 83 & 106 & 135 & 128 & 57 & 51 & 81 & 75 & 118 & 89 & 47 & 99 & 117 \\
2 & 85 & 143 & 25 & 109 & 69 & 66 & 80 & 70 & 47 & 89 & 154 & 150 & 117 \\
3 & 44 & 85 & 67 & 63 & 27 & 36 & 50 & 24 & 14 & 54 & 3 & 27 & 89 \\
4 & 67 & 175 & 135 & 80 & 56 & 37 & 15 & 102 & 22 & 52 & 206 & 159 & 14 \\
5 & 213 & 253 & 15 & 181 & 306 & 119 & 122 & 286 & 162 & 4 & 270 & 150 & 163 \\
6 & 246 & 203 & 508 & 14 & 93 & 235 & 168 & 75 & 227 & 585 & 118 & 182 & 94 \\
7 & 44 & 21 & 31 & 35 & 42 & 10 & 37 & 10 & 65 & 37 & 14 & 92 & 87 \\
8 & 43 & 67 & 88 & 33 & 19 & 29 & 66 & 9 & 65 & 56 & 13 & 6 & 41 \\
9 & 472 & 0 & 35 & 149 & 482 & 237 & 366 & 517 & 260 & 326 & 2 & 211 & 0 \\
10 & 198 & 37 & 119 & 145 & 315 & 99 & 98 & 182 & 285 & 220 & 541 & 208 & 10 \\
11 & 48 & 0 & 46 & 5 & 19 & 27 & 37 & 0 & 9 & 58 & 81 & 0 & 0 \\
12 & 93 & 19 & 0 & 5 & 39 & 217 & 0 & 0 & 35 & 11 & 0 & 0 & 147 \\
13 & 43 & 61 & 75 & 3 & 20 & 21 & 1 & 24 & 52 & 0 & 99 & 68 & 119 \\
14 & 103 & 7 & 107 & 9 & 48 & 152 & 43 & 86 & 165 & 294 & 28 & 0 & 286 \\
15 & 27 & 12 & 132 & 25 & 2 & 23 & 0 & 26 & 55 & 0 & 109 & 1 & 19 \\
16 & 15 & 3 & 48 & 64 & 0 & 10 & 0 & 0 & 0 & 0 & 48 & 0 & 3 \\
17 & 514 & 0 & 0 & 0 & 122 & 347 & 1129 & 0 & 0 & 0 & 0 & 0 & 278 \\
18 & 166 & 0 & 143 & 0 & 0 & 355 & 2 & 0 & 0 & 104 & 53 & 0 \\
19 & 348 & 0 & 0 & 0 & 9 & 401 & 115 & 0 & 18 & 880 & 213 & 0 & 197 \\
20 & 103 & 0 & 0 & 172 & 0 & 7 & 103 & 99 & 134 & 1 & 48 & 0 \\
$\mathrm{U}$ & 211 & 10 & 161 & 112 & 365 & 237 & 140 & 35 & 133 & 14 & 1 & 66 & 80 \\
& & & & & & & & & & & & 0 & 0 \\
\end{tabular}

Table 4. Mean daily southern Alberta precipitation (in $\mathrm{mm}$ ) for each month and $50 \mathrm{kPa}$ synoptic type, for the period $1960-69$. $\mathrm{T}$ : synoptic type number; $\mathrm{U}$ : unclassified

\begin{tabular}{|c|c|c|c|c|c|c|c|c|c|c|c|c|c|}
\hline $\mathrm{T}$ & Year & Jan & Feb & Mar & Apr & May & Jun & Jul & Aug & Sep & Oct & Nov & Dec \\
\hline 1 & 0.912 & 0.848 & 0.776 & 0.757 & 0.740 & 0.743 & 2.208 & 0.958 & 1.303 & 1.192 & 0.263 & 0.608 & 0.975 \\
\hline 2 & 0.934 & 1.147 & 0.144 & 0.645 & 0.892 & 0.954 & 2.179 & 0.888 & 0.520 & 1.198 & 0.849 & 0.924 & 0.972 \\
\hline 3 & 0.488 & 0.680 & 0.385 & 0.374 & 0.353 & 0.521 & 1.350 & 0.305 & 0.155 & 0.733 & 0.021 & 0.169 & 0.747 \\
\hline 4 & 0.733 & 1.401 & 0.773 & 0.475 & 0.721 & 0.532 & 0.413 & 1.296 & 0.250 & 0.703 & 1.134 & 0.980 & 0.116 \\
\hline 5 & 2.323 & 2.027 & 0.089 & 1.076 & 3.941 & 1.720 & 3.310 & 3.623 & 1.788 & 0.063 & 1.490 & 0.922 & 1.362 \\
\hline 6 & 2.679 & 1.623 & 2.895 & 0.084 & 1.207 & 3.389 & 4.527 & 0.961 & 2.495 & 7.821 & 0.650 & 1.118 & 0.787 \\
\hline 7 & 0.480 & 0.170 & 0.182 & 0.210 & 0.540 & 0.156 & 1.015 & 0.133 & 0.719 & 0.507 & 0.079 & 0.567 & 0.727 \\
\hline 8 & 0.473 & 0.535 & 0.508 & 0.197 & 0.256 & 0.417 & 1.780 & 0.115 & 0.721 & 0.752 & 0.073 & 0.039 & 0.347 \\
\hline 9 & 5.149 & 0.000 & 0.202 & 0.884 & 6.207 & 3.409 & 9.874 & 6.540 & 2.864 & 4.373 & 0.014 & 1.281 & 0.000 \\
\hline 10 & 2.159 & 0.299 & 0.683 & 0.862 & 4.055 & 1.433 & 2.648 & 2.313 & 3.138 & 2.950 & 2.986 & 1.273 & 0.085 \\
\hline 11 & 0.527 & 0.007 & 0.264 & 0.032 & 0.248 & 0.395 & 1.021 & 0.000 & 0.108 & 0.786 & 0.446 & 0.000 & 0.000 \\
\hline 12 & 1.016 & 0.159 & 0.000 & 0.033 & 0.506 & 3.131 & 0.000 & 0.009 & 0.389 & 0.149 & 0.000 & 0.000 & 1.234 \\
\hline 13 & 0.474 & 0.487 & 0.433 & 0.019 & 0.261 & 0.312 & 0.029 & 0.310 & 0.579 & 0.012 & 0.545 & 0.419 & 0.991 \\
\hline 14 & 1.131 & 0.059 & 0.615 & 0.057 & 0.626 & 2.191 & 1.179 & 1.097 & 1.818 & 3.893 & 0.157 & 0.000 & 2.363 \\
\hline 15 & 0.303 & 0.097 & 0.758 & 0.153 & 0.028 & 0.338 & 0.014 & 0.337 & 0.617 & 0.000 & 0.605 & 0.011 & 0.166 \\
\hline 16 & 0.173 & 0.024 & 0.277 & 0.382 & 0.000 & 0.146 & 0.000 & 0.000 & 0.000 & 0.000 & 0.268 & 0.000 & 0.031 \\
\hline 17 & 5.669 & 0.000 & 0.000 & 0.000 & 1.573 & 4.993 & 30.158 & 0.000 & 0.000 & 0.000 & 0.000 & 0.000 & 2.298 \\
\hline 18 & 1.821 & 0.000 & 0.827 & 0.000 & 0.000 & 5.150 & 0.056 & 0.000 & 0.000 & 1.398 & 0.297 & 0.000 & 0.000 \\
\hline 19 & 3.760 & 0.000 & 0.000 & 0.000 & 0.127 & 5.817 & 3.103 & 0.000 & 0.205 & 11.828 & 1.165 & 0.000 & 1.656 \\
\hline 20 & 1.136 & 0.000 & 0.000 & 1.021 & 0.000 & 0.111 & 2.795 & 1.271 & 1.468 & 0.014 & 0.269 & 0.000 & 0.000 \\
\hline $\mathrm{U}$ & 2.309 & 0.081 & 0.924 & 0.666 & 4.703 & 3.421 & 3.785 & 0.453 & 1.476 & 0.196 & 0.008 & 0.412 & 0.667 \\
\hline
\end{tabular}

predictive sense, the monthly precipitation totals for the $1970-89$ period were calculated using

$$
P_{m}=\sum_{k=1}^{20}\left(n_{k} \times \overline{P_{m k}}\right)
$$

where $P_{m}$ is the total synthetic precipitation in month $m, n_{k}$ is the number of occurrences of $50 \mathrm{kPa}$ synoptic type $k$ in month $m$, and $\overline{P_{m k}}$ is the mean daily precipitation falling in month $m$ with synoptic type $k$ (as in Table 4). More involved statistical techniques have been developed by Bardossy \& Plate (1992), and employed in the U.S. Great Plains (e.g. Matyasovszky et al. 1994). Despite greater mathematical complexities, results are still dependent on which GCM is used. This 
serves to underline the fact that widely different views of future climate scenarios are possible regardless of the approach used to derive them.

The results of applying Eq. (4) to southern Alberta are shown in Fig. 7. Overall, the greater the time integration, the better the results. The time series of monthly synthetic precipitation indicated that the general seasonality was captured reliably, but that the timing of extremes was not always coeval: in several years the months with extreme high precipitation were not coincident (Fig. 7a, b). The predicted mean monthly precipitations were generally close to the observed value (Fig. $7 \mathrm{C}$ ), and for 8 months there were no significant differences between the two. However, the variability of the observed monthly precipitation far outweighed that of the predicted; this was also true of the interannual variability (Fig. 7d). However, the total amounts of precipitation falling in each decade were very similar: for
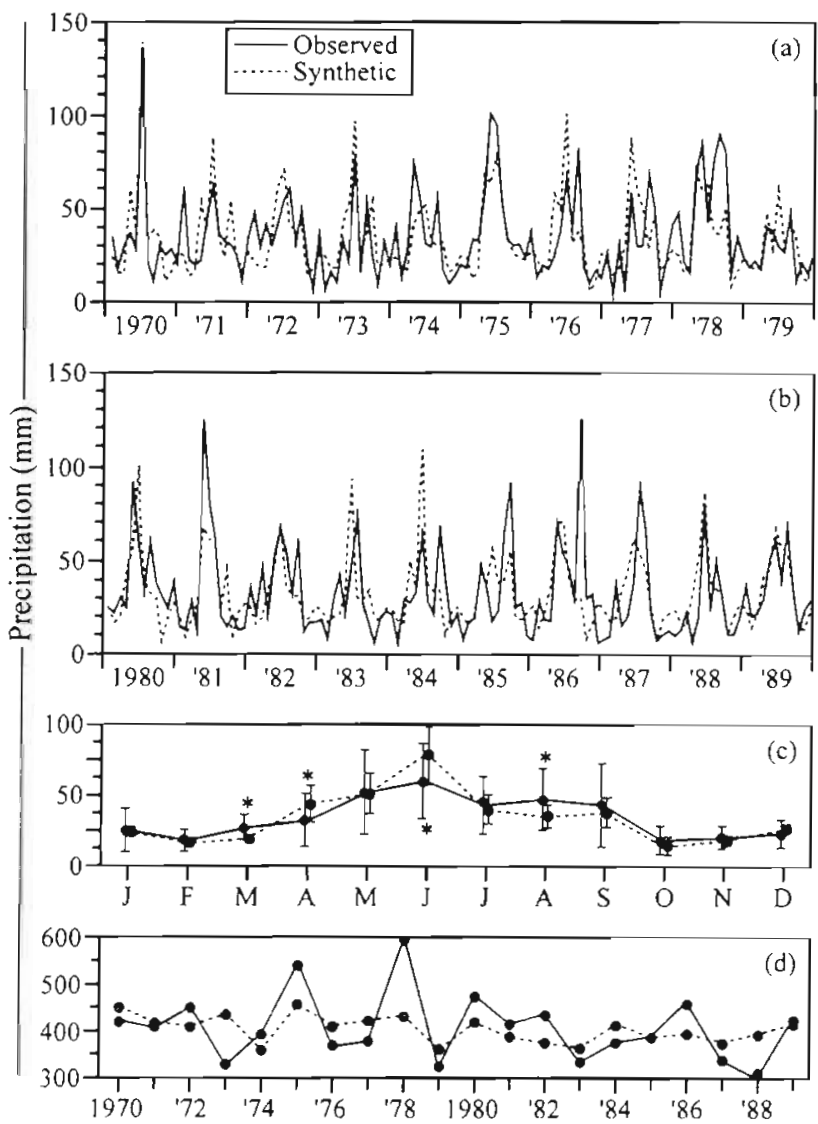

Fig. 7. Observed precipitation in southern Alberta (solid line) compared to synthetic precipitation generated by Eq. (4) (dashed line). (a) Monthly precipitation, 1970-79. (b) Monthly precipitation, 1980-89. (c) Mean monthly precipitation \pm 1 SD. Months with a star (*) indicate where the means are significantly different. With the exception of April and June, all variances are significantly different. (d) Total annual precipitation, 1970-89
1970-79, observed and synthetic precipitation were 4217 and $4159 \mathrm{~mm}$, and for 1980-89 they were 3950 and $3924 \mathrm{~mm}$. The methods thus offered reliable estimates of the bulk amounts of precipitation.

\section{SYNTHETIC PRECIPITATION GENERATED USING GCM CLIMATOLOGY}

\section{1. $1 \times \mathrm{CO}_{2}$ atmosphere simulations}

Overall, the above procedure using Eq. (4) to generate time series of synthetic precipitation produced results which were plausible, albeit with unrealistic variabilities. Such a simplistic approach as used here could not be expected to be able to include all features of a precipitation regime for any area, and especially so for an area where convective precipitation is so important, since the processes occur at scales substantially smaller than synoptic.

As a measure of intercomparison, synthetic monthly precipitation was generated using Eq. (4) and using the CCC GCMII $1 \times \mathrm{CO}_{2} 50 \mathrm{kPa}$ pressure fields as input (hereafter termed 'GCM-synthetic'), then compared to the observed climatology and the precipitation modelled directly by the $1 \times \mathrm{CO}_{2}$ run of the CCC GCMII itself (hereafter termed 'GCM-generated'). The GCMsynthetic data was a better simulation of monthly precipitation than the GCM-generated (Fig. 8a); the latter typically produced gross overestimates of precipitation (as discussed by Saunders \& Byrne 1994), although the variability was more realistic (Fig. 8 b). The $1 \times \mathrm{CO}_{2}$ GCM-generated precipitation was significantly different from the observed precipitation in all months except June and September, and lacked noticeable seasonality. Conversely, the GCM-synthetic precipitation tracked the observed quite closely, only differing in May. Therefore using the GCM $50 \mathrm{kPa}$ pressure fields to generate precipitation rather than using the GCM-generated precipitation resulted in a more realistic output.

\section{2. $2 \times \mathrm{CO}_{2}$ atmosphere simulations}

Finally, the changes in GCM-generated and GCMsynthetic precipitation arising from a simulated doubling of atmospheric $\mathrm{CO}_{2}$ were examined. Monthly precipitation was generated using Eq. (4) and $2 \times \mathrm{CO}_{2}$ CCC GCMII $50 \mathrm{kPa}$ pressure fields in order to determine the changes between $1 \times \mathrm{CO}_{2}$ and $2 \times \mathrm{CO}_{2}$ regimes. There is little difference in the frequency of occurrence of $50 \mathrm{kPa}$ pressure fields in each run of the CCC GCMII (Fig. 9a), so it could be anticipated that there would be minimal changes to the precipitation regime. Alternatively, it is feasible that only small 


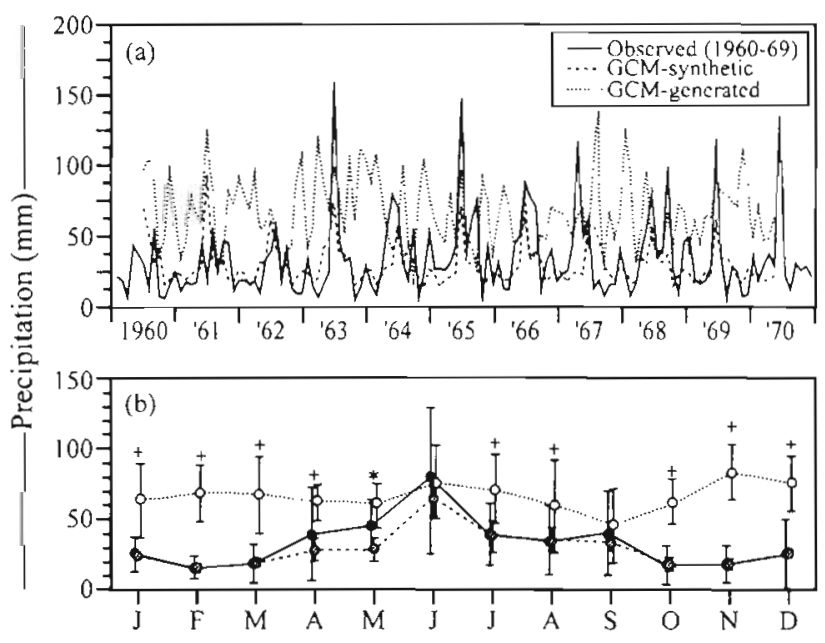

Fig. 8. Comparisons between observed, GCM-synthetic and GCM-generated precipitation for: (a) monthly precipitation for $1960-70$ (observed) or GCM years 1 to 11 (the $10 \mathrm{yr}$ of GCM data begins at June, Year 1, and ends at May, Year 11); (b) mean monthly precipitation, with error bars indicating \pm 1 SD. Crosses ( + ) indicate where GCM-generated precipitation means are significantly different from the observed. Stars (*) indicate the same for both GCM-generated and GCMsynthetic precipitation means

changes in the frequency of a synoptic type with a very high or low precipitation efficiency would result in significant changes to the total monthly precipitation. This was not the case, however, and the $1 \times \mathrm{CO}_{2}$ and $2 \times \mathrm{CO}_{2}$ GCM-synthetic precipitation time series are almost identical (Fig. 9b), confirming that very little change in the synoptic control of precipitation in southern Alberta occurred.

Fig. 9c shows that differences between the $2 \times \mathrm{CO}_{2}-$ atmosphere GCM-synthetic and GCM-generated time series are similar to those in the $1 \times \mathrm{CO}_{2}$ case (shown in Fig. 8a); the GCM-generated precipitation showed much greater variability and overall a much wetter regime than the GCM-synthetic. Differences in the mean precipitation changes arising from doubled $\mathrm{CO}_{2}$ conditions were generally similar (Fig. 9d) although, as before, the variabilities were very different. Despite differences in the magnitude of change, both the GCM-generated and GCM-synthetic data showed a general agreement between the direction of changeboth suggested a wetter spring and a drier summer.

\section{CLOSING COMMENTS}

Employing a simple synoptic type frequency approach to the generation of synthetic precipitation resulted in a reasonable simulation of mean annual and monthly precipitation amounts, although variabil-
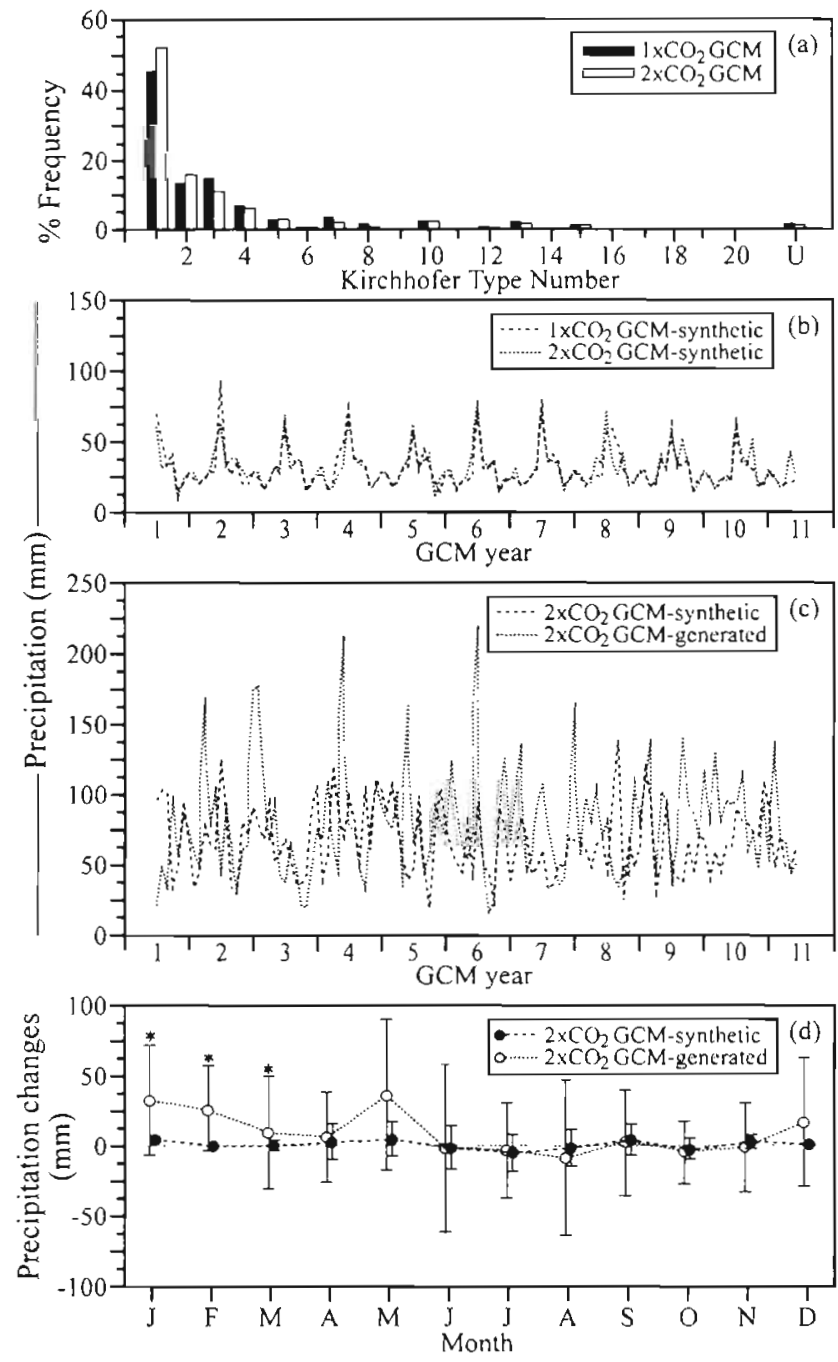

Fig. 9. Comparisons between GCM-synthetic and GCM-generated precipitation under $1 \times \mathrm{CO}_{2}$ and $2 \times \mathrm{CO}_{2}$ conditions. (a) Occurrence histogram of $50 \mathrm{kPa}$ synoptic type frequencies in the CCC GCMII. (b) Monthly GCM-synthetic precipitation for 10 yr $1 \times \mathrm{CO}_{2}$ and $2 \times \mathrm{CO}_{2} \mathrm{CCC}$ GCMII runs (the $10 \mathrm{yr}$ of $\mathrm{CCC}$ GCMII data begins at June, Year 1, and ends at May, Year 11). (c) Monthly GCM-synthetic and GCM-generated precipitation for the $10 \mathrm{yr} 2 \times \mathrm{CO}_{2} \mathrm{CCC}$ GCMII run. (d) Mean precipitation changes arising from doubled $\mathrm{CO}_{2}$ conditions for GCM-synthetic and GCM-generated precipitation, with error bars indicating $\pm 1 \mathrm{SD}$. Stars (*) indicate where a pair of monthly means are significantly different. All 12 pairs of variances are significantly different

ities were smaller than the observed. Using the same method with GCM pressure data produced a synthetic precipitation regime that was more realistic than that generated by the GCM itself. Overall, the approach offers a simple means of generating precipitation scenarios for applications where total amounts of monthly and yearly precipitation need to be reliable.

The main drawback to using this approach is the apparent inability to accurately represent the ex- 
tremely wet months. However, the impact of not predicting the wettest months is not that important. Most hydrologic extremes for the study area are related to heavy snow years on the plains and/or in the mountains (Byrne 1989, Byrne \& McNaughton 1991) - these the method predicts well. Even rain on deep snow should be predictable - heavy regional snowfall will be synoptically (cyclonically) generated, as will any rainfall of significance occurring in the spring during the snowmelt period.

The wettest months are likely combined synopticconvective summer months. These are only important hydrologically on a local basis (field flooding, etc.). Too much summer rain has not been a problem in the past. More important concerns are that droughts and winter precipitation, which are both important to the hydrology in the study area, are synoptically controlled and are reliably reproduced by the present method.

The utility of the methodology for generating synthetic precipitation time series may be limited by several points, including:

(1) The method is too simplistic. Expecting a strong relationship between synoptic-scale and local-scale events to hold true at all times in all places is unrealistic.

(2) Precipitation in the study area is strongly affected by sub-grid vorticity patterns and related microand meso-scale precipitation. In these instances, a reliable connection between synoptic type frequency and local precipitation may not be established. This is most likely in late spring, summer and early fall, when convective processes dominate precipitation received over much of the study area. However, for late fall, winter and early spring, cyclonic scale processes dominate precipitation activity. The synoptic type - precipitation linkage is strong for these periods.

(3) There must be some variability of spatial pressure patterns within each synoptic type grouping (this was also considered to be problematic by Barry et al. 1981). This cannot be avoided, although narrowing the tolerance limits in the Kirchhofer technique could reduce the problem (but at the expense of many more keydays being generated).

(4) The derivation of synoptic types, while inherently objective, is dependent on the spatial scales of the pressure data used to generate them. Therefore, using a different grid point spacing or a different size of window could conceivably produce a different set of keydays. In the case of southern Alberta summer precipitation, this is probably not so important because of the convective nature of much of the rainfall, but for winter snowfall in the Rocky Mountains this might be a critical issue, since cyclonic controls are much greater.
Acknowledgements. Dennis Sheppard (University of Lethbridge) assisted in the acquisition and retrieval of the NCAR pressure data. Alan Barr and Sean McGinn (Agriculture Canada, Lethbridge) provided the observed precipitation data. The Atmospheric Environment Service supplied output from the CCC GCMII. Assistance with the application of the Kirchhofer technique was kindly donated by Ian McKendry (University of British Columbia). The comments of 2 anonymous reviewers were gratefully received.

\section{LITERATURE CITED}

Bardossy A, Plate E (1992) Space-time model for daily rainfall using atmospheric circulation patterns. Wat Resour Res 28:1247-1260

Barry RG (1980) Synoptic and dynamic climatology. Prog Phys Geog 4:88--96

Barry RG, Kiladis G, Bradley RS (1981) Synoptic climatology of the western United States in relation to climatic fluctuations during the twentieth century. J Climatol 1:97-113

Boer GJ, McFarlane NA, Laprise R, Henderson JD, Blanchet JP (1984) The Canadian Climate Centre spectral atmospheric general circulation model. Atmos-Ocean 22 $397-429$

Byrne JM (1989) Three phase runoff model for small prairie rivers. 1. frozen soil phase assessment. Can Wat Res J 14: $17-28$

Byrne JM, McNaughton RB (1991) Predicting temporal and volumetric changes in runoff regimes under climate warming scenarios. Can Wat Res J 16:129-141

Changnon D, McKee TB, Doesken NJ (1993) Annual snowpack patterns across the Rockies: long-term trends and associated $500-\mathrm{mb}$ synoptic patterns. Mon Weather Rev 121:633-647

Crane RG, Barry RG (1988) Comparison of the MSL synoptic pressure patterns of the Arctic as observed and simulated by the GISS general circulation model. Meteorol Atmos Phys 39:169-183

El-Kadi AKA, Smithson PA (1992) Atmospheric classifications and synoptic climatology. Prog Phys Geog 16:432-455

Hay LE, McCabe GJ, Wolock DM, Ayers MA (1991) Simulation of precipitation by weather type analysis. Wat Resour Res 27:493-501

Hewitson B, Crane RG (1992) Regional climates in the GISS global circulation model: synoptic-scale circulation. J Climate 5:1002-1011

Johnson EA, Wowchuk DR (1993) Wildfires in the southern Canadian Rocky Mountains and their relationship to mid-tropospheric anomalies. Can J Forest Res 23: $1213-1222$

Knox JL, Lawford RG (1990) The relationship between Canadian prairie dry and wet months and circulation anomalies in the mid-troposphere. Atmos-Ocean 28:189-215

Matyasovszky I, Bogardi I, Duckstein L (1994) Comparison of two general circulation models to downscale temperature and precipitation under climatic change. Wat Resour Res 30:3437-3448

McFarlane NA, Boer GJ, Blanchet JP, Lazare M (1992) The Canadian Climate Centre second-generation. general circulation model and its equilibrium climate. J Climate 5: 1013-1044

McKendry IG, Steyn DG, McBean G (in press) Valıdation of synoptic circulation patterns simulated by the Canadian Climate Centre General Circulation Model for western North America. Atmos-Ocean 
Saunders IR, Byrne JM (1994) Annual and seasonal climate and climatic changes in the Canadian prairies simulated by the CCC GCM. Atmos-Ocean 32:621-641

Stenning AJ, Banfield CE, Young GJ (1981) Synoptic controls over katabatic layer characteristics above a melting glacier. J Climatol 1:309-324

Wilson LL, Lettenmaier DP, Wood, EF (1991) Simulation of daily precipitation in the Pacific Northwest using a weather classification scheme. Surv Geophys 12:127-142

Yarnal B (1984a) Synoptic-scale atmospheric circulation over

Editor: V. Meentemeyer, Athens, Georgia, USA
British Columbia in relation to the mass balance of Sentinel Glacier. Ann Ass Am Geogr 74:375-392

Yarnal B (1984b) A procedure for the classification of synoptic weather maps from gridded atmospheric pressure surface data. Comp Geosci 10:397-410

Yarnal B (1985) A $500 \mathrm{mb}$ synoptic climatology of Pacific north-west coast winters in relation to climatic variability, 1948-1949 to 1977-1978. J Climatol 5:237-252

Yarnal B (1993) Synoptic climatology in environmental analysis. Belhaven Press, London

Manuscript first received: July 18, 1995

Revised version accepted: December 4, 1995 